\title{
An Exquisite Case of \\ Giant Occipital Meningocele \\ Following Aplasia of Occipital Bone
}

\section{Sushma DARIPELLI}

Department of Anatomy, Senior Resident, All India Institute of Medical Sciences, Bibinagar, Telangana,508126, India

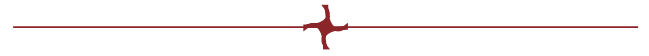

\begin{abstract}
-ABSTRACT
Cephaloceles are the neural tube defects occurring at a rate of one per 5000 live births worldwide. It indicates herniation of meninges or meninges with brain tissue through defect in the cranium. We describe an interesting case report of a one-day old male neonate with giant occipital meningocele with aplasia of occipital bone. This is the first case with a history of consanguinity reported in the literature so far. The size of the meningocele sac was greater than the that of the head. A plain computed tomography of the brain showed a $136 \mathrm{~mm} \times 129 \mathrm{~mm}$ well defined cerebrospinal fluid attenuated hypodense lesion herniating through calvaria defect on occipital region, with no neural elements, suggestive of giant occipital meningocele. All efforts should be made to diagnose cranial or spinal dysraphism during antenatal screening meticulously following a careful history taking, clinical examination and ultrasonography scan in the first trimester, followed by folic acid supplementation, mandatory through legislation.
\end{abstract}

Keywords: cranial dysraphism, giant meningocele, neural tube defects, occipital meningocele.

\section{INTRODUCTION}

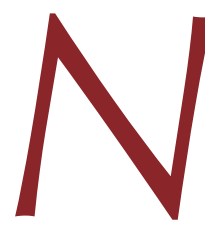

eural tube defects (NTD) are the second most common serious birth defects affecting between $0.3-10$ per 1000 live births (1). Neural tube defects result from complex interactions of genes and environmental conditions (2). The incomplete closure of the upper end of the neural tube during embryogenesis leads to cranial meningocele. Meningoceles are skin covered lesions containing meningeal tissue that has herniated through the posterior vertebral column or defect in calvaria. Most of the cephaloceles occurring in the occipital region involve supraoccipital or, less commonly, in the interparietal part of the occipital bone; sincipital cephaloceles are less frequent and basal cephaloceles are rare (3). Meningomyelocele and acrania are birth defects of multifactorial etiology. Other risk factors

\footnotetext{
Address for correspondence:

Dr. Sushma Daripelli,

Department of Anatomy, All India Institute of Medical Sciences, Bibinagar, Telangana, 508126, India

Tel.: 09989199159

Email Id: sushma.tulips@gmail.com
} 
include exposure to teratogens, tryptan blue, arsenic, viral infections, diabetes, maternal obesity and maternal smoking (4). Studies reveal that low levels of folic acid, vitamins and riboflavin during early pregnancy are associated with NTD (5).

\section{CASE REPORT}

one-day old male neonate with a weight of $3.2 \mathrm{~kg}$, born at term following caesarian section, was referred to the neonatal intensive care unit (NICU) with features of occipital meningocele. The infant's life was precious, given that his mother had three spontaneous abortions and no live siblings. There was no family history of any congenital malformation or NTD. No antenatal radiological tests were performed as the case was not referred antenatally. On examination of the neonate, all hematological investigations were normal. The swelling was increasing in size during crying and coughing. The anterior fontanel was wide open and on palpation there was a breach in underlying cranium at the level of the occipital region (Figure 1). On examination, a giant occipital tense cystic swelling measuring $120 \times 100 \mathrm{~mm}$, larger than neonate's head, was noted using a positive transillumination test. The neonate was active and there was no other congenital anomalies and neurological defects. The differential diagnosis could be skull defects associated with aplasia cutis congenita, as these defects are usually restricted to skull vertex, so it is ruled out. Non-contrast plain computer tomography of the head showed a well-defined swelling of $136 \times 129 \mathrm{~mm}$, cerebrospinal fluid (CSF) attenuating a hypodense lesion herniating through calvaria defect on the occipital region, with no neural elements suggestive of giant occipital meningocele (Figure 2).

On day three, the neonate was taken for surgery under general anesthesia with a plan of meningocele repair. The sac was decompressed by draining about $870 \mathrm{~mL}$ of clear CSF. A linear incision was given on sac, the meningocele sac was separated from the occipital bone defect. Dura was incised and no neural elements that could be suggestive of meningocele were seen inside. Sac excision along with redundant dura was done and Dural edges were approximated to achieve water tight closure. The occipital bone defect was repaired using autologous split calvaria graft for good cosmetic result. The redun- dant skin was excised and closed esthetically in layers. Postoperative deterioration was fast and the infant died within 24 hours after surgery.

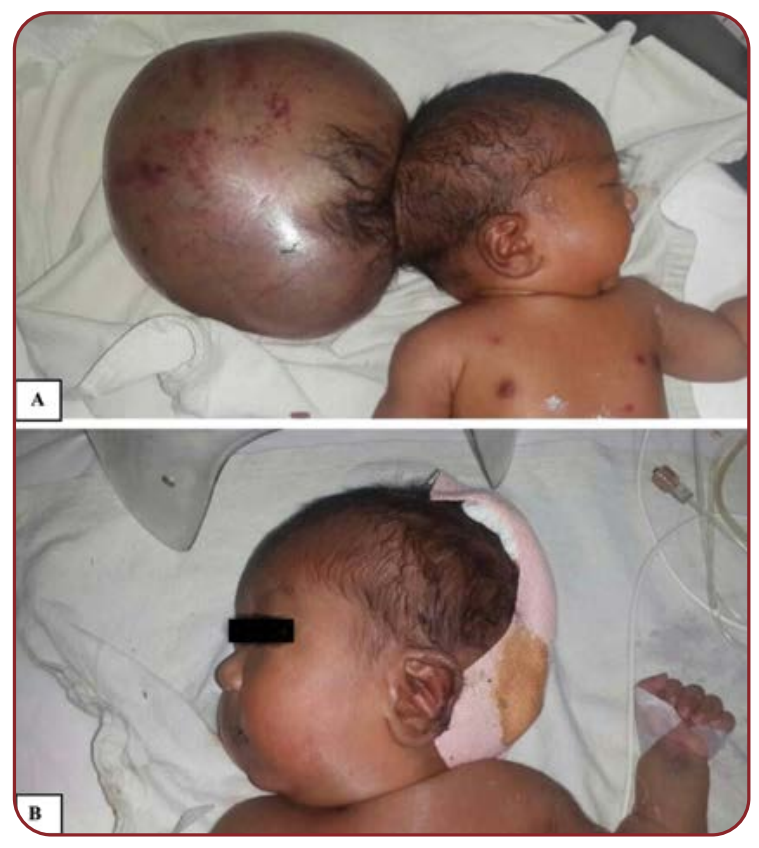

FIGURE 1. Clinical photographs: A) Neonate with giant occipital meningocele before surgery; and B) Neonate after surgery

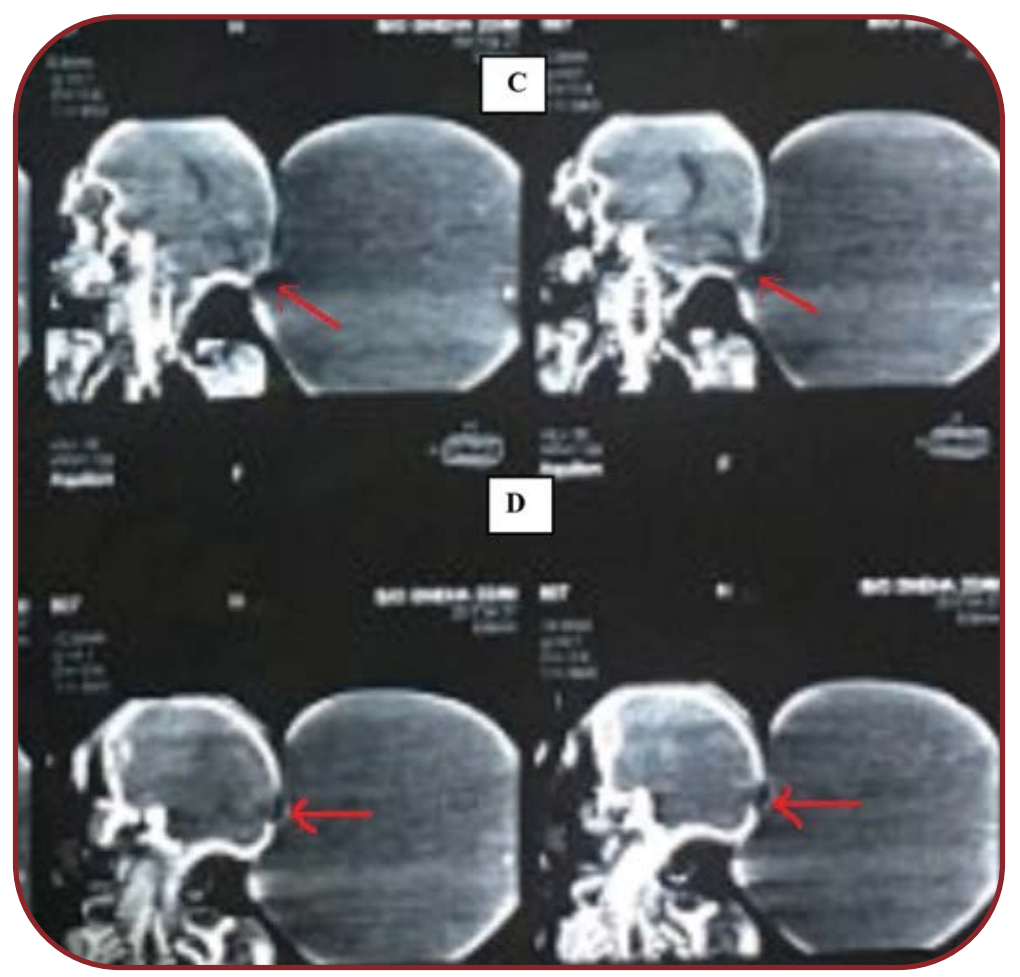

FIGURE 2. Sagittal computed tomography scan head:

A, B) Small bony defect (arrow) with a giant occipital meningocele communicating with a large posterior fossa cyst; and

C, D): A arrow showing defect in occipital bone 


\section{DISCUSSION}

N eural tube defects such as meningomyelocele and acrania are birth defects of multifactorial etiology, where both environment and genetic factors play a major role. Agenesis of cranial bones is rare condition incompatible with life. The primary abnormality in the development of a meningocele is a mesodermal defect resulting in a defect of calvaria and associated with herniation of CSF and meninges through defect. Occipital meningocele occurs due to aplasia of the occipital bone. Talamonti et al classified occipital meningoceles into categories, small, large and giant, with diameters up to $50 \mathrm{~mm}$ (small), 50-90 mm (large), and $>90 \mathrm{~mm}$ (giant) (6). Usually, the size of occipital meningocele progressively increases as raised intracranial pressure leads to compensatory CSF escape into the sac with the child's growth.

In the present case, the neonate was investigated and diagnosed as aplasia of occipital bone with secondary giant occipital meningocele. The human occipital bone is a composite bone developed from two sources. The parachordal cartilage surrounding the cephalic part of notochord fuses to form the basal plate, then it is continuous with the occipital sclerotomes, the lamina of which meet behind, forming the foramen magnum and squamous part of the occipital bone. The intraparietal part of the occipital bone develops from membranous ossification (8). In the case reported by us, the defect was produced by failure of fusion of these two parts of the occipital bone. In 2011, Torbjorn et al presented a case of meningocele with occipital aplasia which showed balanced and familiar translocation between chromosomes 3 and 9 (7). None of the breakpoint regions (3p21.3 and 9q22.3, both gene rich $\mathrm{R}$ bands) are known to harbour genes with a known or potential role in neural tube development. Most likely, the translocation is a random finding unrelated to rare phenotype. The disruption of a gene or more long range regulatory or epigenetic changes effect genes in the vicinity of translocation breakpoints contributed to phenotype. This balanced translocation was inherited from normal father and grandfather
(7). In the present case, since the neonate was born to paternal consanguinity of first cousin marriage, one of the causes might be due to translocation of genes. The only treatment in this case is surgical excision of sac, followed by repair of cranial defect, i.e., decompression, dura plasty, autologous split calvaria graft.

Previous studies showed eight rare cases of giant meningocele, larger than each patients' head, while some were associated with encephalocele, Dandy Walker syndrome (DWS) and craniovertebral anomalies, and others with aplasia of the occipital bone $(6,9-13)$. However, the current case represented a unique case of giant OMC with aplasia of the occipital bone and, to the best of our knowledge, was the third male neonate case of day one and first reported case with the outcome of consanguineous marriage ever reported. The prognosis of the case after surgery was unfavorable. The incidence of these defects has a descending trend due to the use of pre-pregnancy folic acid medication, antenatal sonography in the first trimester, and amniocentesis in recurrent abortions, which should be maid mandatory. Also, awareness of consanguineous marriages was low in this case. In the present study, the family could not seek pre-pregnancy advice due to poor socioeconomic status. Surgical treatment should be performed on urgent basis, within few days, to decrease the risk of rupture and nursing care inconveniences, given that advances in microsurgery and neuro anesthesia have been shown to reduce surgical complications.

\section{CONCLUSION}

A II efforts should be made to meticulously diagnose cranial or spinal dysraphism during antenatal screening, followed by mandatory folic acid supplementation on legal basis. It is a useful approach, which would help reduce the incidence of NTDs and early diagnosis and treatment.

Conflicts of interest: none declared.

Financial support: none declared. 


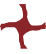

\section{R}

1. Gupta N, Ross ME. Disorders of Neural Tube Development. In:

Swaiman's Pediatric Neurology. Sixth edition. Swaiman KF, Ashwal S, Shevell MI, editors, Elsevier. 2017, pp 183-191.

2. Shallow TA. Spina bifida and cranial meningocele.

Ann Surg 1928;87:811-822.

3. O'Rahilly R. Anomalous occipital apertures. Arch Pathol 1952;53:509-519.

4. Manning SM, Jennings R, Madsen JR. Pathophysiology, prevention and potential treatment of neural tube defects. Ment Retard Dev Disable Res Rev 2000;6;6-14.

5. Copp AJ, stainer P, Greene ND. Neural tube defects: recent advances, unsolved questions, and controversies. Lancet Neurol 2013;12;799-810.
6. Talamonti G, Picano M, Debernardi A, et al. Giant occipital meningocele in an 8-year-old child with Dandy-Walker malformation.

Childs Nerv Syst 2011;27:167-174.

7. Eggebo TM, Brathetland J, Dirdal HU, Houge G. Meningocele following aplasia of the occipital bone. BMJ Case Rep 2011. doi:10.1136/ bcr.10.2010.3437.

8. Shapiro R, Robinson F. Embryogenesis of human occipital bone. Am J Roentgenol 1976;126:1063-1068.

9. Walia B, Bhargava P, Sandhu K. Giant Occipital Encephalocele.

Med J Armed Forces India 2011. doi:10.1016/S0377-1237(05)80181-9.

10. Singh R, Dogra N, Jain P, Choudhary S. Dandy Walker syndrome with giant occipital meningocele with craniovertebral anomalies: challenges faced during anesthesia.

Indian J Anaesth 2016;60:71-73.

11. Mankotia DS, Satyarthee GD, Singh B, Sharma BS. A rare case of giant occipital meningocele with Dandy Walker Syndrome: can it grow bigger than this? I Pediatric Neurosci 2016;11:344-347. doi:10.4103/1817-1745.

12. Chaturvedi J, Goyal N, Arora RK, Govil N. Giant Occipitocervical Encephalocele. Neuro Sci Rural Pract 2018;9:414-416. doi: 10.4103/jnrp.jnrp_24_18.

13. Sreekanta PM, Kumar S. Giant Occipital Encephalocele in an Infant: A Surgical Challenge.

J Pediatric Neurosci 2019;14:218-221.

Published online 2019 Dec3. doi:10.4103/jpn.JPN_115_18. 